\title{
Study on the electrochemical corrosion and scale growth of ductile iron in water distribution system. PART II
}

\author{
Yimei Tian, Chuntong Liu, Hao Guo*, Haiya Zhang, Xingfei Liu, Ying Chen
}

Department of Environmental Engineering, School of Environmental Science and Engineering, Tianjin University, Tianjin 300350, China

*E-mail: tjuguohao@163.com

doi: $10.20964 / 2018.11 .41$

Received: 5 July 2018 / Accepted: 22 August 2018 / Published: 1 October 2018

Long-term contact with carried water makes water supply pipes prone to electrochemical corrosion, which will lead to pipelines leaking or bursting. In this study, a flow corrosion simulation and monitoring system (FCSMS) was designed to systematically study the factors influencing internal corrosion of ductile iron pipes. By using the linear polarization resistance (LPR) method, EIS and the polarization curve test, it was determined how five influencing factors (including temperature and $\mathrm{pH}$ ) affect the corrosion rate, corrosion scale structure and anodic and cathodic reactions. Then, the effect mechanism of each influencing factor in the internal corrosion process was expounded, and the importance of the influencing factors was determined by correlation analysis: temperature $>\mathrm{pH}>$ dissolved oxygen> total hardness > total residual chlorine.

Keywords: water supply pipe, corrosion scale, influencing factors, EIS, polarization curve

\section{FULL TEXT}

(C) 2018 The Authors. Published by ESG (www.electrochemsci.org). This article is an open access article distributed under the terms and conditions of the Creative Commons Attribution license (http://creativecommons.org/licenses/by/4.0/). 